\title{
Research report \\ Activity-dependent plasticity in visual forebrain areas of the zebra finch
}

\author{
Astrid Rollenhagen, Hans-Joachim Bischof * \\ Fakultät Biologie, Universität Bielefeld, Lehrstuhl für Verhaltensforschung, Postfach 100131, 33501 Bielefeld, Germany
}

Received 22 December 1995; revised 27 March 1996; accepted 27 March 1996

\begin{abstract}
It has previously been shown that the activity of some areas of the forebrain of birds is dependent on the arousal level of the animal. Other areas do not show this dependency. This paper, on the basis of 2-DG experiments and spine density measurements on Golgi-impregnated tissue, shows that primary telencephalic target areas of the two visual pathways of zebra finch males are not dependent on arousal for activation. In contrast, secondary areas of both visual pathways show arousal-dependent activation. Only the secondary visual areas also show effects of rearing conditions on the spine density: isolation of the birds from day 40 reduces spine density in the hyperstriatum accessorium (HA) of the thalamofugal pathway, and enhances spine density in the lateral neo/hyperstriatum (LNH, tectofugal pathway) significantly from day 80, if compared to aviary-reared birds. A 1-week exposure to a female eliminates the isolation effects in both areas. A second isolation period again reduces the spine density in the HA, but does not enhance it again in the LNH. By comparison with previous studies, we conclude that the spine density in the HA reflects the complexity of the social environment. The irreversible reduction of spine density in the LNH as consequence of the 7-day exposure to a female is interpreted as physiological correlate of an imprinting process, which has previously been shown to occur at the same time. The effects in both areas, the $\mathrm{HA}$ and $\mathrm{LNH}$, are dependent on arousal, which may be mediated by brainstem efferents innervating the secondary, but not the primary, visual areas in birds and in mammals.
\end{abstract}

Keywords: Bird; Mammal; Arousal; Visual system; Learning; Imprinting; Development; 2-Deoxyglucose; Golgi impregnation

\section{Introduction}

2-Deoxyglucose (2-DG) studies in zebra finches [5,6] and chicks [18] indicated that the activation pattern of the telencephalon of birds depends not only on sensory stimulation, but also on the general arousal level of the animal. Four areas of the forebrain are activated only if the stimulus is arousing: the hyperstriatum accessorium and dorsale (HAD), the lateral part of the neo- and hyperstriatum (LNH), the medial part of the neo- and hyperstriatum (MNH) and the caudal part of the archiand neostriatum (ANC). One of these areas, the $\mathrm{MNH}$, has been shown to be involved in filial imprinting [27]. These authors also demonstrated that the density of $\mathrm{MNH}$ neuron dendritic spines is reduced by imprinting. In zebra finches which were exposed to a female for the first time after being isolated from independence to adulthood ('first courtship'), the spine density of $\mathrm{MNH}$

* Corresponding author. Tel.: (49) (521) 106-2712; Fax: (49) (521) 106-2998; E-mail: bischof@post.uni-bielefeld.de neurons is also drastically reduced [22]. This reduction is not reversible by subsequent isolation of the bird. In contrast, the spine density of ANC neurons is enhanced by the same treatment, and this enhancement is reversible by subsequent isolation. Rollenhagen and Bischof [22] speculated in line with the findings of Wallhäusser and Scheich [27] that the irreversible reduction of spines within the MNH may be the anatomical manifestation of the imprinting process, which has been shown [4] to occur in an experimental situation identical to that used in their study. Rollenhagen and Bischof $[21,22]$ further proposed that the complexity of the neuronal net of the ANC follows the complexity of the social environment, and that the level of arousal is the most important factor influencing the complexity of the neuronal net.

As yet, nothing was known about the plasticity of the other two areas, the LNH and HAD, which are activated only in aroused birds. To examine this would be extremely interesting because the function of these two areas is much better known compared with that of the $\mathrm{MNH}$ and ANC. The LNH and HAD are the secondary 
telencephalic projection areas of the two main visual pathways in birds. The thalamofugal pathway leads from the retina to the thalamic relay nucleus geniculatus lateralis pars dorsalis (Gld) and further to the so-called 'visual wulst' [12]. The visual wulst is subdivided into at least 4 constituents (but see [23]). These include the hyperstriatum accessorium (HA) the intercalate nucleus of the hyperstriatum accessorium (IHA), the hyperstriatum intercalatus superior (HIS) and the hyperstriatum dorsale (HD). Projections from the thalamus terminate mainly in the IHA [14]. The visual information is then relayed to the other layers of the visual wulst. These layers, the $\mathrm{HA}$ and $\mathrm{HD}$, show additional activation in arousing situations in zebra finches. The HIS has, as yet, not been identified in these birds $[5,6]$.

Within the tectofugal pathway, visual information is conveyed from the eye to the optic tectum, then to the $n$. rotundus, and further to the core region of the ectostriatum. From the ectostriatal core, information is processed to the surrounding ectostriatal belt and further to the adjacent neostriatum, the NIL (neostriatum intermedium laterale) $[12,20]$, which is part of the $\mathrm{LNH}$, another of the 'arousal' areas revealed by the studies of Bischof and Herrmann $[5,6]$. It therefore appears as if the additional activation of telencephalic areas by arousal can only be observed in secondary projection areas of the two visual pathways. The activity of primary sensory areas are probably not affected by arousal, as previous measurements of field $\mathbf{L}$, an acoustic area, suggested $[5,6]$.

In the present study, we tested whether the idea of the restriction of arousal-dependent activation to secondary telencephalic sensory areas could be verified for the two visual pathways. We also wanted to know whether changes of spine density, as described by Rollenhagen and Bischof [22], could also be observed in the visual secondary areas. Last, but not least, we examined the development of spine densities for the areas where we found alterations of activation by the first courtship of previously isolated males.

\section{Materials and methods}

\subsection{2-Deoxyglucose study}

Eight males zebra finches from the institute's breeding colony were isolated at 40 days of age, after reaching independence. They were kept in single cages, where they could hear, but not see other zebra finches. At day 100 , the 2-DG experiment was performed. The birds were given an injection of $12 \mu \mathrm{Ci}\left[14^{\mathrm{C}}\right] 2-\mathrm{DG}$ (NEN) in $0.1 \mathrm{ml}$ physiological saline into the pectoral muscle. Half of the birds were then exposed to a female for $1 \mathrm{~h}$. The others, serving as controls, were put into an empty cage. At the end of the experiment, the birds were decapitated. The brains were quickly removed from the skull, immedi- ately frozen onto a cryostat head and cut into $30-\mu \mathrm{m}$ transverse sections. The mounted sections were dried, exposed to Kodak X-ray film at $4^{\circ} \mathrm{C}$ for 4 weeks, and developed with Kodak D I9 developer.

Quantitative measurements of the densities of labeled structures were obtained by a computer-based densitometric system (Image 1.47, NIH). For each bird and each area, at least 5 density measurements were performed in consecutive sections. From the means of these measurements, a score of relative densities was calculated, based on the values of the lowest level of a given brain (Area $X, 0 \%$ ) and a constantly very high label (field L, 100\%). Differences between the scores of the different groups were tested by Mann-Whitney U-tests.

\subsection{Golgi experiments}

Sixty male zebra finches were used for the Golgi study. The experimental design is illustrated in Fig. 1. All birds were reared by their natural parents in aviaries. For Golgi Expt. 1, 8 birds were isolated at day 40 as in the 2-DG experiment. Four of these birds were exposed to a female from day 100 to day 107 (first courtship group, Fig. 1,3), the others left in isolation until day 107 (isolates, Fig. 1,2). Four other birds were left in the aviary until day 107 (aviary group, Fig. 1,1). All animals were processed for histology at day 107 (arrows in Fig. 1,1-3).

By Golgi Expt. 2, the developmental changes of spine densities within the areas of interest were investigated in aviary-reared birds of the following age groups: 10 , $20,30,60,70$ and 80 days $(n=4$ for each age group, arrows in Fig. 1,1). Birds isolated at day 40 were processed for histology at days 60,70 and $80(n=4$ for each age group). The values for 107 days of age were taken

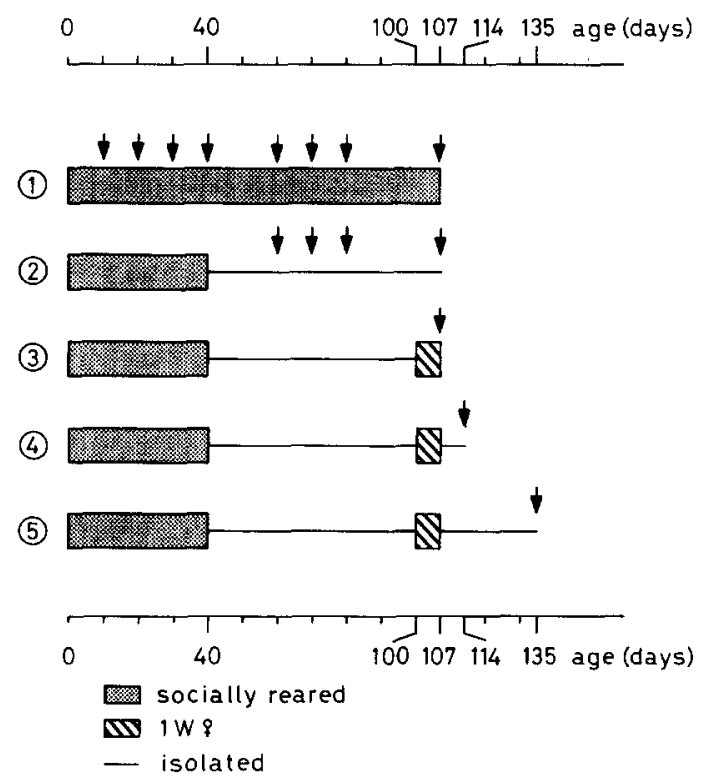

Fig. 1. Experimental design. Numbers 1-5 depict the different experimental groups. For further explanation see methods section. 
for both, the isolated and the aviary reared group, from Golgi Expt. 1. Because we were interested in the stability of the observed changes, we also examined two groups of 4 males each which were isolated for 1 (Fig. 1,4) or 4 weeks (Fig. 1,5) after the end of the 1-week exposure to a female.

At the ages indicated above (arrows in Fig. 1), the birds were deeply anesthetized and perfused with $0.9 \%$ $\mathrm{NaCl}$ followed by $10 \%$ formaldehyde. After processing the brains according to a modification of the Bubenaite Golgi method [10], 100- $\mu \mathrm{m}$ transverse vibratome sections were made. In all brain areas, a neuron type characterized by a soma diameter of about $5-10 \mu \mathrm{m}$ and 4-6 radially ordered dendrites with relatively few dendritic spines could be identified. At least 5 such fully impregnated neurons of each brain area of interest were analyzed on drawings, made with the help of a drawing tube attached to a Zeiss microscope at a magnification of $1250 \times$ under oil. For the measurements, only those of the terminal sections of the dendrites were selected, which were parallel to the surface of the slides. Terminal sections were chosen because earlier studies have shown that these are most strongly affected by experience $[6,21,22]$. After drawing the selected terminal sections (up to 4 per neuron, in total 20 for each bird and area), the number of spines $/ 10 \mu \mathrm{m}$ was estimated with the help of a graphics tablet. No attempt was made to correct for hidden spines [7].

Data collection was performed 'blind' in the sense that coded slides were not uncoded until all measurements had been made. For statistical analysis, the mean value of all measurements per area of interest was calculated for each bird. These values were used as the basis for further statistics. Differences between groups were then tested by Kruskal-Wallis $H$-test with post hoc $U$-tests. As the computed calculations of significance provided by most statistical packages are incorrect for numbers below 5, the significances (two-tailed) were determined using a table provided by Siegel [24] for small samples. Differences were claimed as significant if $P$ was smaller than 0.028 .

\section{Results}

\subsection{2-Deoxyglucose experiments}

It is obvious, by inspection, that in the behavioral situation without a female (without an arousing stimulus) only the primary visual areas are strongly active. Fig. 2A shows the visual wulst of a non-aroused zebra finch male. Only the IHA shows strong activation. At its dorsolateral part, the IHA ends in a larger patch of heavy label. We could not decide by inspection of adjacent Nissl sections whether the IHA layer becomes stronger here or whether the strong patch may represent an extra area which was called hyperstriatum laterale

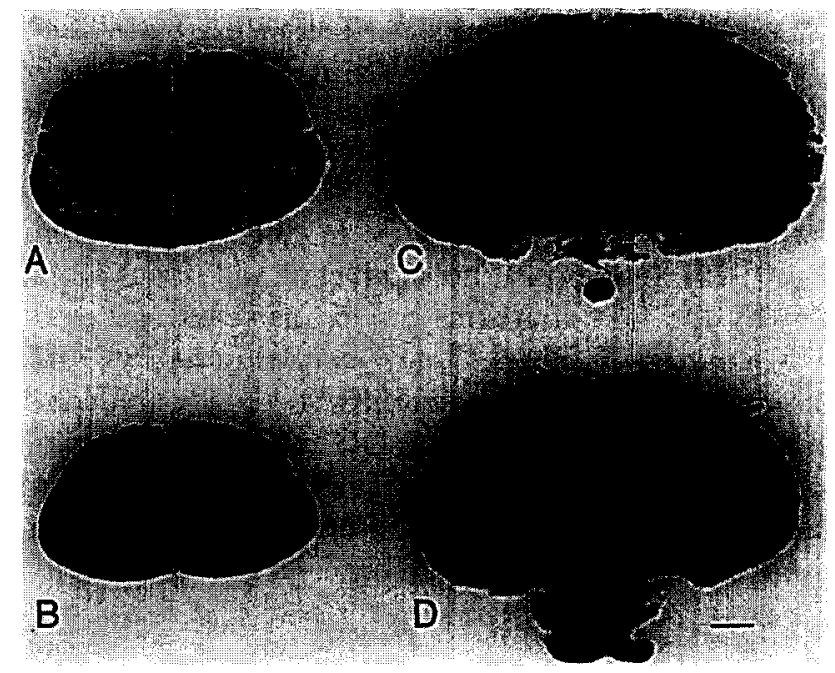

Fig. 2. 2-DG autoradiographs from coronal sections of the anterior (A, $B)$ and the medial (C, D) forebrain of two male zebra finches. A, C: control. B, D: first exposure to a female at 100 days of age. HA, hyperstriatum accessorium; IHA, nucleus intercalatus hyperstriati accessorii; HD, hyperstriatum dorsale; LNH, lateral neo/hyperstriatum; E, ectostriatum; dashed line in B, location of IHA as determined from the original sections which was Nissl-stained after exposure to autoradiographic film. Calibration bar: $1 \mathrm{~mm}$. HA/HD and LNH are more activated in the 'first courtship' group.

(H1) by Shimizu and Karten [23]. Because of this uncertainty, this area was not included in the analysis. Fig. 2B shows the brain of an aroused male. The dark zone showing the incorporation of radioactive 2-DG extends from the IHA into the HA and also into part of the HD. Fig. $2 \mathrm{C}$ shows the ectostriatal region in a non-aroused bird. In Fig. 2D, of an aroused bird, the active zones extend into the lateral neostriatum and into the hyperstriatum.

Fig. 3 depicts the measurements of the 4 areas of interest in non-aroused and in aroused animals. These measurements confirm that the activity of the HA and $\mathrm{LNH}$ are enhanced in aroused birds, while the IHA and

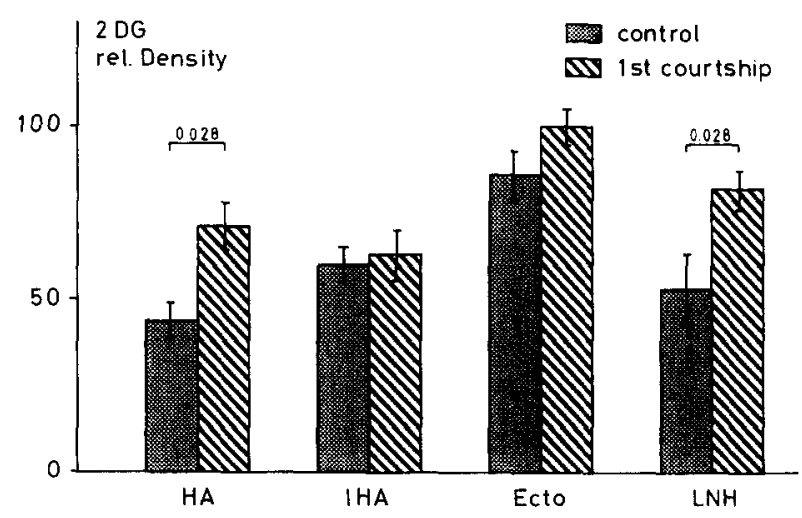

Fig. 3. Relative optical densities in brain areas of control (stippled bars) and 'first courtship' (hatched bars) animals. Means and SEMs. For calculation of relative densities see methods section. For abbreviations see Fig. 2. Significant differences were obtained only within the HA and LNH. 
the ectostriatum do not show significant enhancement. The relative optical densities within the $\mathrm{HA}$ are $42.85 \pm 8.88$ in the control animals and $68.75 \pm 13.73$ in the aroused (first courtship) animals $(P \leq 0.028)$. The densities measured within the LNH are $52.20 \pm 18.59$ in the controls and $79.92 \pm 9.78$ in the aroused birds $(P \leq 0.028)$. In contrast, no significant additional activation by the first courtship can be detected within the IHA (controls $58.59 \pm 9.17$, first courtship $61.35 \pm 17.21$, NS) and ectostriatum (controls $83.51 \pm 14.86$, first courtship $96.99 \pm 9.89$, NS). The 2-DG experiment therefore confirms our first hypothesis that enhancement of neuronal activity by arousal can be observed only in secondary visual areas of the telencephalon.

\subsection{Golgi Expt. 1}

The results of the spine density measurements are depicted in Fig. 4. The $\mathrm{H}$-test confirms that there are significant differences between groups. The spine densities measured within the HA are $4.49 \pm 0.31$ spines $/ 10 \mu \mathrm{m}$ in isolates, $6.14 \pm 0.27$ spines $/ 10 \mu \mathrm{m}$ in aviary-reared birds, and $5.71 \pm 0.14$ spines $/ 10 \mu \mathrm{m}$ in the animals which were exposed to a female for 1 week after previous isolation $(H=8, P \leq 0.01)$. The difference between isolates and aviary-reared birds as well as those between the isolate and the 'first courtship' group is significant $(P \leq 0.028)$. If one considers the aviary rearing as the 'normal' condition, isolation during development reduces the spine density of HA neurons, and this reduced density is enhanced to values comparable to those of aviary-reared birds, if the bird is exposed to a female for 1 week after isolation.

The LNH shows another pattern of changes due to the experimental conditions. Spine density in aviaryreared birds is $5.04 \pm 0.12$ spines $/ 10 \mu \mathrm{m}$, in isolates

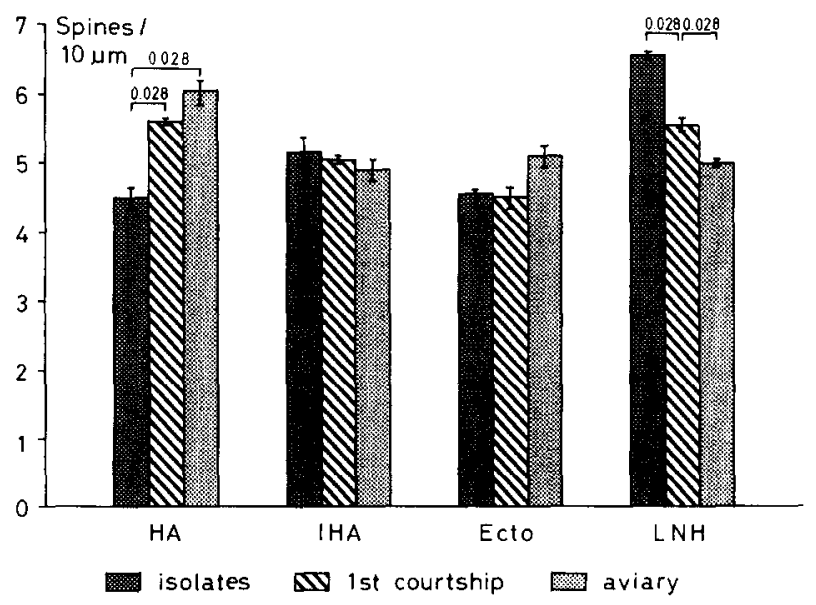

Fig. 4. Spine counts in 4 brain areas of zebra finches, raised under 3 different conditions. For abbreviations see Fig. 2. Significant differences between isolates and the two other conditions were only obtained within the HA and LNH.
$6.59 \pm 0.08$ spines $/ 10 \mu \mathrm{m}$, and $5.56 \pm 0.15$ spines $/ 10 \mu \mathrm{m}$ in the 'first courtship' group $(H=9.27, P \leq 0.01)$. Only the differences between isolates and aviary-reared birds, and between isolates and the 'first courtship' group, are significant $(P \leq 0.028)$.

Again considering the aviary conditions as 'normal', isolation enhances the spine density within the $\mathrm{LNH}$, and subsequent exposure to a female leads to a reduction. This is exactly the reverse pattern compared to the effects within the HA.

As in the 2-DG study, no significant differences between the 3 different rearing conditions could be obtained for ectostriatum $(H=3.5, \mathrm{NS}$; aviary $5.25 \pm 0.31$ spines $/ 10 \mu \mathrm{m}$, isolates $4.6 \pm 0.14$ spines $/ 10 \mu \mathrm{m}$, first courtship $4.5 \pm 0.32$ spines $/ 10 \mu \mathrm{m})$ and IHA $(H=2.63$, NS; aviary $4.78 \pm 0.25$ spines $/ 10 \mu \mathrm{m}$, isolates $5.28 \pm 0.35$ spines $/ 10 \mu \mathrm{m}$, first courtship $5.14 \pm 0.1$ spines $/ 10 \mu \mathrm{m}$ ). These experiments confirm our second idea that plasticity, as indicated by changes of spine density, can only be seen in areas which also show enhanced activity in arousing situations.

\subsection{Golgi Expt. 2}

This series of experiments was aimed to answer two questions. First, at which time does the observed difference of spine densities in the LNH and HA develop? Second, are the effects of the first courtship experiment stable or can they further be affected by subsequent isolation?

The development of the spine density of $\mathrm{HA}$ and $\mathrm{LNH}$ neurons is depicted in Figs. 5 and 6, respectively. The solid line shows the development in aviary-reared animals, the broken line that of spine density in animals isolated from day 40 (at this time, the young birds are independent from their parents and therefore can be separated). The bars at the right of Figs. 5 and 6 shows the results of the different treatments after day 100 (see Expt. 1 and methods section).

The spine density of the HA neurons (Fig. 5) shows a strong increase between days 10 and 20 , and then a decrease towards a minimum at 70 days. Thereafter, the densities increase again until the 'adult' value of $6.14 \pm 0.38$ spines $/ 10 \mu \mathrm{m}$ is reached at 107 days of age. The spine densities obtained in isolated animals at 60 days (broken line) are significantly lower than those of aviary-reared birds. They meet the values obtained in aviary-reared birds at 70 days, and thereafter decline further to the 107 day value of $4.49 \pm 0.31$ spines $/ 10 \mu \mathrm{m}$. This is significantly $(P \leq 0.028)$ lower than that measured in aviary-reared birds.

The first two bars on the right of Fig. 5 reiterate the values obtained at 107 days in aviary (A) reared and isolated (ISO) birds, respectively. If the isolated birds are exposed to a female at day 100 for 7 days $(1 \mathrm{~W}$ ? $)$, the spine density increases significantly. It does not, 


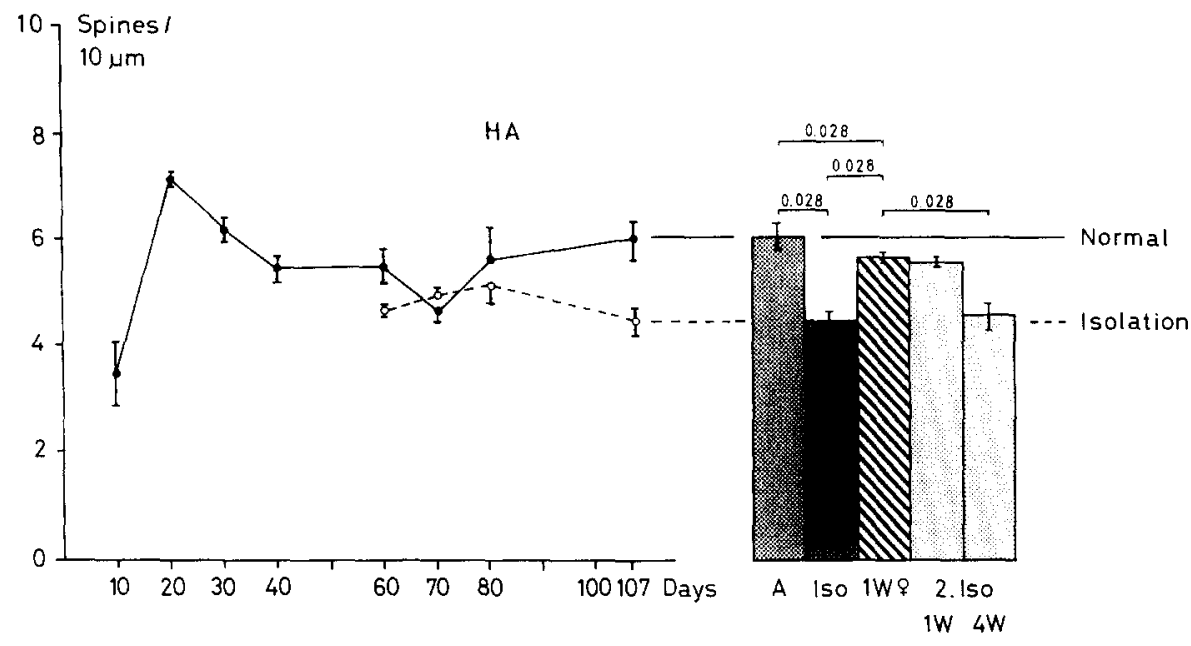

Fig. 5. Development and plasticity of spine density within the hyperstriatum accessorium (HA). Solid line, aviary-reared animals ('normal'); dashed line, isolated birds. Bars: effects of different rearing conditions on spine density on HA neurons. A, aviary-reared birds, ISO, isolated; 1 Wo, 1-week exposure to a female; 2 . ISO, isolation after exposure to a female for 1 week $(1 \mathrm{~W})$ or 4 weeks $(4 \mathrm{~W})$. For further explanation see methods section. All values with SEMs. Significant differences are indicated by horizontal bars with $P$-values.

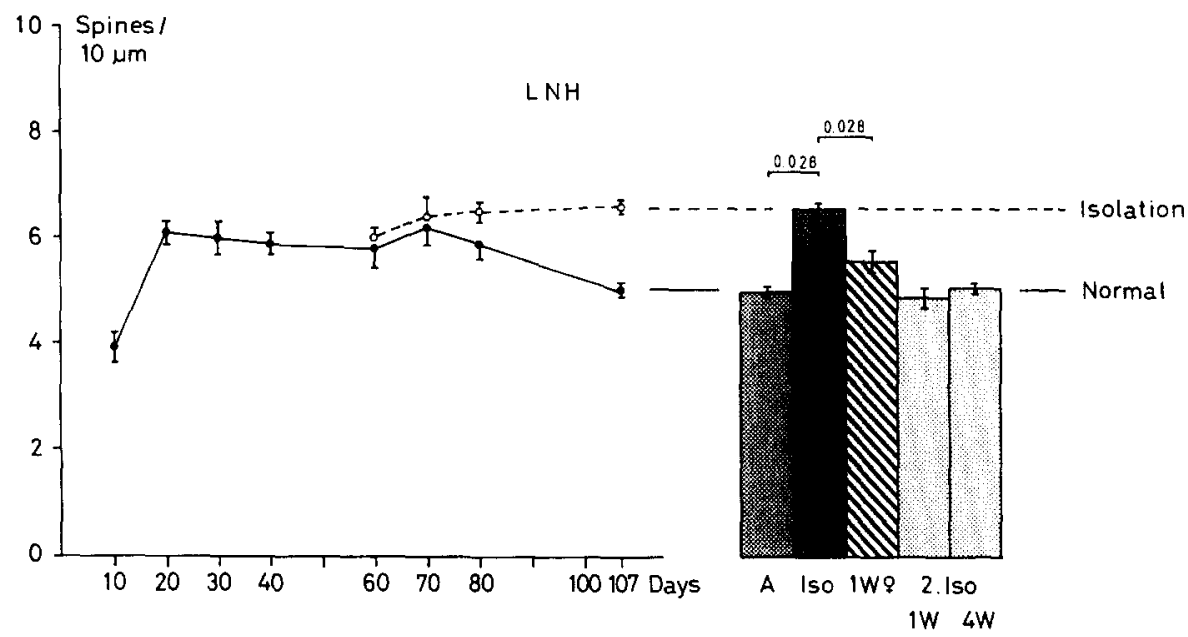

Fig. 6. Development and plasticity of spine density within the lateral neo/hyperstriatum (LNH). Solid line, aviary-reared animals ('normal'); dashed line, isolated birds. Bars: effects of different rearing conditions on spine density on LNH neurons. A, aviary-reared birds; ISO, isolated; 1 WO, 1-week exposure to a female; 2 . ISO, isolation after exposure to a female for 1 week $(1 \mathrm{~W})$ or 4 weeks $(4 \mathrm{~W})$. For further explanation see methods section. All values with SEMs. Significant differences are indicated by horizontal bars with $P$-values.

however, reach the density of the aviary reared group. One week of isolation after the 7-day exposure $(1 \mathrm{~W}$ ISO) does not alter the spine density of HA neurons. However, by 4 weeks of isolation (4 W ISO), the density decreases again, and reaches a value comparable to that obtained in isolated animals.

The development of spine density within the LNH (Fig. 6) is different from that observed in the HA. The increase from day 10 to day 20 in aviary-reared birds (solid line) is smaller than that obtained for the HA, and the decline after the peak at 20 days is very slow and lasts, without significant intermediate discontinuities, until day 107. The 60- and 70-day values in isolated animals (broken line) are not significantly different from those in aviary-reared birds.
Surprisingly, the value obtained at 80 days is higher in isolated animals (although not significantly different from the aviary group), and this enhancement continues until day 107 , where a density of $6.59 \pm 0.08$ spines $/ 10 \mu \mathrm{m}$ is reached, which is significantly $(P \leq 0.028)$ higher than that of aviary-reared animals $(5.04 \pm 0.12$ spines $/ 10 \mu \mathrm{m})$.

The first two bars on the right of Fig. 6 again show the 107-day densities obtained in aviary-reared (A) and isolated (ISO) birds, respectively. Exposing isolated birds after 100 days to a female $(1 \mathrm{~W}$ ) for 7 days leads to a decreased spine density within the LNH $(5.56 \pm 0.15$ spines $/ 10 \mu \mathrm{m})$. Subsequent isolation further decreases the densities $(4.92 \pm 0.20$ spines $/ 10 \mu \mathrm{m}$ after 1 week isolation ( $1 \mathrm{~W}$ ISO), and $5.12 \pm 0.12$ spines $/ 10 \mu \mathrm{m}$ after 4 weeks (4 W ISO) of isolation. 


\section{Discussion}

Our results clearly demonstrate that both primary visual areas of the telencephalon, the IHA of the visual wulst and the ectostriatum, are active quite independent of the arousal state of the animal. Their activity is only slightly higher in arousing situations, and the difference is not significant. It is plausible that these areas maintain a certain level of activity in every situation, because some basic level of processing should go on at any time, at least if the animal is awake and alert. Whether the activity of the primary visual telencephalic areas is decreased in the dark or during sleep, has still to be examined.

Although our results cannot be interpreted as to indicate that the secondary areas are not involved in basic level processing of visual areas, they unequivocally show that these areas are more activated in arousing situations. Because nothing is known about the differences between the processing capabilities of neurons in the primary and secondary areas of the two visual systems of birds, we can only speculate that the stronger activation of the machinery of the secondary areas may enhance the processing capabilities and capacity of the telencephalic stations of the visual system. Similar ideas have been evolved for processing within the visual cortex of mammals. Livingstone and Hubel [17] showed with 2-DG that activation of layer 4 of area 17 in cats, which is the target of the thalamic efferents, is not strongly affected by the arousal state of the animal. In contrast, the activity of the deeper layers is strongly enhanced in alert compared to drowsy animals. Livingstone and Hubel [17] also showed that cortical neurons in aroused animals showed a better signal to noise ratio and an enhanced reaction to visual stimuli. Singer et al. [26] showed that the enhanced activation of deeper and upper layers may be due to concomitant activation of these layers by the reticular formation. Karten [12] and Karten and Shimizu [13] provided evidence that the primary sensory areas of the two visual pathways in birds, the IHA and the ectostriatum, may be homologous to layer 4 of the mammalian extrastriate and striate visual cortex, respectively. The HA and LNH are, according to these authors, homologous to other layers of the visual cortices. If this is true, the mechanisms proposed for the activation of cortical areas in mammals may also be valid for the visual telencephalic areas in birds.

This idea may also be supported by the fact that efferents from the reticular formation or locus coeruleus are described to terminate mainly in superficial and deeper layers of the mammalian visual cortex, not in layer 4 [8]. Likewise, the avian brain regions $\mathrm{HA}$ and LNH receive input from the reticular formation and other brainstem nuclei which are involved in the regulation of the arousal state of the animal $[1,15,16]$, while the IHA and ectostriatum do not receive such input.
The strong effect of a direct activation of higher cortical layers (or secondary visual areas in birds) by reticular efferents questions the role of the reticular projections to the thalamic relay nuclei [9], which have been demonstrated in mammals and in birds. It has been shown that the access of sensory information to the cortex is gated by this input: the stronger the reticular activation, the more information is conveyed via the thalamic nuclei towards the cortical areas [25]. This mechanism, however, should also lead to stronger activation of the input layers of the cortex (or the primary visual areas in birds). Although we could not confirm this in our study, we believe that both mechanisms of reticular activation may work together. We observed a slight enhancement of activation in both primary areas, which was, however, not significant. Our method was probably not sensitive enough or the number of experimental animals was too small to make these differences significant. If so, one could propose that the reticular activation works in two steps, first by gating of sensory activation within the thalamic relay nuclei, and second, by direct enhancement of the responsiveness of the outer and inner layers of the visual cortex (or the secondary visual areas in birds).

The second part of our study clearly shows that plastic changes of spine density as a result of exposure to a female are restricted to the secondary areas of the two visual systems, that is the areas which also show arousaldependent activation. Our experiment does not provide hints why this is the case. However, the most parsimonious explanation would be that the innervation by the brainstem also affects the plastic potency of the neurons. Although this is plausible for the first view, one has to consider that the plastic changes are different in the HA and LNH. While exposure to a female for 7 days leads to an enhancement of spine density within the HA of previously isolated birds, the same treatment induces a reduction of spine density within the LNH.

In addition, the enhancement in the HA is reversible by subsequent isolation, while the reduction within the LNH is not. These differences call for different mechanisms of regulation of plastic changes, and as yet one cannot decide whether the input from the brainstem may act (via different intermediate processes) on both types of plasticity, or whether there are different inputs from the brainstem. It is also possible that the difference causing the two types of plasticity is not at the presynaptic side, but may be located postsynaptically (e.g., different second messengers). Last, but not least, it cannot be excluded that the different plastic changes observed in the LNH and HA are not caused by different input properties, but may be due to different intrinsic (functional) properties of the neurons. This has to be examined by further immunohistochemical work.

The present results are not the first to show such different forms of plasticity resulting from the same 
behavioral experiment. We have previously shown [22] that the spine densities of neurons of the two other 'arousal' areas of the zebra finch forebrain react almost identical to early isolation, exposure to a female for 7 days at day 100 , and subsequent isolation. The time course of spine density development in these two other areas is also very similar to those described here. The results obtained in this study for the HA are very similar to those described in our previous study for an area called the ANC (archi/neostriatum caudale). The results obtained are for the LNH are almost identical to those of an area called the MNH (medial neo/hyperstriatum).

In the previous study [22], we provided examples of regressive and instructive plasticity in birds and mammals. We concluded from a survey of the existing literature that regressive plasticity (a reduction of spines) is predominantly found in developing animals, as, for example, in the development of the visual cortex (for review see [2,3]) or in filial imprinting in chicks [27]. We presumed that the non-reversible regression of dendritic spines, which we observed in the MNH after the first courtship situation, normally occurs earlier in development and is delayed in our experiment by isolation. The same explanation can probably be applied for the LNH. If so, this area may also be involved in sexual imprinting, which can likewise be delayed by isolation until day $100[4,11,19]$. The HA, in contrast, seems to increase and decrease the complexity of the neuronal net depending on the (social) complexity of the environment: if the bird is isolated, the complexity of the neuronal net within the HA is lower than in situations with social companions. This seems plausible if one considers that a more complex network may be needed to adequately process a more complex environment. As already mentioned in the introduction, there is a wealth of evidence from other animals which supports this notion [22].

\section{References}

[1] Bagnoli, P. and Burkhalter, A., Organization of the afferent projections to the wulst in the pigeon, J. Comp. Neurol., 214 (1983) 103-113.

[2] Bischof, H.-J., Imprinting and cortical plasticity: a comparative review, Neurosci. Biobehav. Rev., 7 (1983) 213-225.

[3] Bischof, H.-J., Environmental influences on early development: a comparison between imprinting and cortical plasticity. In: P.P.G. Bateson and P.H. Klopfer (Eds.), Perspectives in Ethology, Vol. 6, Mechanisms, Plenum Press, New York, 1985, pp. 169-217.

[4] Bischof, H.-J. and Clayton, N., Stabilization of sexual preferences by sexual experience in male zebra finches (Taeniopygia guttata castanotis), Behaviour, 118 (1991) 145-155.

[5] Bischof, H.-J. and Herrmann, K., Arousal enhances ${ }^{14} \mathrm{C}$-deoxyglucose uptake in four forebrain areas of the zebra finch, Behav. Brain Res., 21 (1986) 215-221.

[6] Bischof, H.-J. and Herrmann, K., Isolation dependent enhance- ment of 2-14C deoxyglucose uptake in the forebrain of zebra finch males, Behav. Neural Biol., 49 (1988) 386-397.

[7] Feldman, M.L. and Peters, A., A technique for estimating total spine numbers on Golgi-impregnated dendrites, J. Comp. Neurol., 188 (1979) $527-542$.

[8] Garey, L. Synaptic organization of afferent fibres and intrinsic circuits in the neocortex. In: O. Creutzfeld (Ed.), Handbook of Electroencephalography, Vol. IIa, 1976, pp. 58-84.

[9] Güntürkün, O., Miceli, D. and Watanabe, M., Anatomy of the avian thalamofugal pathway. In: H.P. Zeigler, and H.-J. Bischof (Eds.), Vision, Brain, and Behavior in Birds, 1993, pp. 116-135.

[10] Herrmann, K. and Bischof, H.-J., Development of neurons in the ectostriatum of normal and monocularly deprived zebra finches: a quantitative Golgi study, J. Comp. Neurol., 277 (1988) 141-154.

[11] Immelmann, K., Pröve, R., Lassek, R. and Bischof, H.-J., Influence of adult courtship experience on the development of sexual preferences in zebra finch males, Anim. Behav., 42 (1991) 83-89.

[12] Karten, H.J., The organization of the avian telencephalon and some speculations on the phylogeny of the amniote telencephalon, Ann. New York Acad. Sci., 167 (1969) 167-179.

[13] Karten, H.J. and Shimizu, T., Are visual hierarchies in the brain of the beholders? Constancy and variability in the visual system of birds and mammals. In: P. Bagnoli, and W. Hodos (Eds.), The Changing Visual System, Plenum Press. New York, 1991, pp. $51-59$.

[14] Karten, H.J., Hodos, W., Nauta, W.J.H. and Revzin, A.L., Neuronal connections of the 'visual wulst' of the avian telencephalon. Experimental studies in the pigeon (Columba livia) and the owl (Speotyto cunicularia), J. Comp. Neurol., 150 (1973) 253-277.

[15] Kitt, C.A. and Brauth, S.E., Telencephalic projections from midbrain and isthmal cell groups in the pigeon. I. Locus coeruleus and subcoeruleus, J. Comp. Neurol., 247 (1986) 69-91.

[16] Kitt, C.A. and Brauth, S.E., Telencephalic projections from midbrain and isthmal cell groups in the pigeon. II. The nigral complex, J. Comp. Neurol., 247 (1986) 92-110.

[17] Livingstone, M. and Hubel, D.H., Effects of sleep and arousal on the processing of visual information in the cat, Nature, 291 (1981) 554-561.

[18] Müller, S.C. and Scheich, H., Social stress increases $\left({ }^{14} \mathrm{C}\right)$ 2-deoxyglucose incorporation in three rostral forebrain areas of the young chick, Behav. Brain Res., 19 (1986) 93-98.

[19] Oetting, S., Pröve, E. and Bischof, H.-J., Sexual imprinting as a two-stage process: mechanisms of information storage and stabilization, Anim. Behav., 50 (1995) 393-403.

[20] Ritchie, T.L.C. and Cohen, D.H., The avian tectofugal visual pathway: projections of its telencephalon target ectostriatal complex, Soc. Neurosci. Abstr., 2 (1979) 119

[21] Rollenhagen, A. and Bischof, H.-J., Rearing conditions affect neuron morphology in a telencephalic area of the zebra finch, NeuroReport, 2 (1991) 711-714.

[22] Rollenhagen, A. and Bischof, H.-J., Phase specific morphological changes induced by social experience in two forebrain areas of the zebra finch, Behav. Brain Res., 65 (1994) 83-88.

[23] Shimizu, T. and Karten, H.J., Immunhistochemical analysis of the visual wulst of the pigeon (Columba livia), J. Comp. Neurol., 300 (1990) 346-369.

[24] Siegel, S., Nichtparametrische statistische Methoden, Fachbuchhandlung für Psychologie, Frankfurt am Main, 1976.

[25] Singer, W., Central-core control of visual cortex functions. In: F.O. Schmitt, F.G. Worden, F.G. (Eds.), The Neurosciences Fourth Study Program, MIT Press, Cambridge, MA, 1979, pp. $1093-1110$.

[26] Singer, W., Tretter, F. and Cynnader, M., The effect of reticular stimulation on spontaneous and evoked activity in the cat visual cortex, Behav. Brain Res., 102 (1976) 71-90.

[27] Wallhäusser, E. and Scheich, H., Auditory imprinting leads to differential 2-deoxyglucose uptake and dendritic spine loss in the chick rostral forebrain, Dev. Brain Res., 31 (1987) 29-44. 